\title{
PRIMJENA INFRACRVENE TERMOGRAFIJE U DIJAGNOSTICI ELEKTROMOTORA NA TRANSPORTERIMA
}

\author{
DIAGNOSTICS OF ELECTRIC MOTOR DRIVE ON CONVEYORS \\ BY MEANS OF INFRARED THERMOGRAPHY
}

\author{
S. Pliestić, A. Galić, F. Jović, Nadica Dobričevié, \\ Sandra Voća, Jana Šic Žlabur
}

\section{SAŽETAK}

Infracrvena termografija predstavlja novu tehniku mjerenja koja radi na principu pretvaranja toplinske energije emitirane $u$ infracrvenom području elektromagnetskog spektra, u vidljive slike. Ova metoda posjeduje veliki potencijal u beskontaktnom dijagnosticiranju rada pogonskog elektromotora transportera mjerenjem njegove temperature. Primjenom infracrvene termografije moguće je svakodnevno pratiti stanje elektromotora i time pravovremeno reagirati na eventualne kvarove ili štetne promjene koje se javljaju tijekom eksploatacije transportera. U ovom radu analiziran je rad elektromotora transportera primjenom infracrvene kamere Horiba II-1064A. Mjerenja su obavljana na pogonskom elektromotoru $(\mathrm{P}=1,1 \mathrm{~kW})$ pužnog transportera.

Ključne riječi: dijagnostika, elektromagnetski spektar, infracrvena termografija, elektromotor

\begin{abstract}
Infrared thermography is a new technique of measurement, which converts thermal energy emitted in the infrared region of the electromagnetic spectrum, into visible images. This feature presents great potential to non-contact diagnosing of the electric motor drives. By infrared thermography, it is possible on a daily basis, to track electric motors and thus promptly react to any malfunction or adverse changes that occur during conveyor operation. In this paper the work of electric motors is analyzed using infrared camera Horiba II1064. Measurements were performed on the screw conveyor electric motor drive $(\mathrm{P}=1.1 \mathrm{~kW})$.

Keywords: diagnostics, electromagnetic spectrum, infrared thermography, electric motor
\end{abstract}


S. Pliestić i sur.: Primjena infracrvene termografije u dijagnostici elektromotora na transporterima

\section{UVOD}

Tehnički ispravno transportno sredstvo, osnovni je uvjet besprijekornog rada, visokog učinka, optimalne potrošnje pogonske energije, smanjenja troškova, uz pravovremeno obavljanje servisa. Svako transportno sredstvo ima od proizvođača propisan, način rukovanja, puštanja u uporabu i servisnotehničko održavanje. Tehničko stanje transportnih sredstava svih vrsta mijenja se tijekom eksploatacije, jer povećanjem broja sati rada sredstava mijenjanju se odnosno pogoršavaju dinamička i eksploatacijska svojstva. To pogoršanje prouzrokuje trošenje zbog trenja dodirnih površina. Neispravnosti u radu pojedinih mehanizama najčešće se javljaju u obliku raznih nepravilnih šumova kao što su: pregrijavanje, dimljenje, iskrenje, vibracije, brujanje, znojenje, pucketanje, škripanje, lupanje i slično. Trošenje dijelova pojedinih mehanizama i sklopova strojeva i sredstava, pod utjecajem sila koje ih pokreću, a u ovisnosti o satima rada raste progresivno i dovodi do povećanja radnih zazora među njima, odnosno dolazi do promjena tolerancija. Time se smanjuje njihova statička, dinamička izdržljivost. Radna sposobnost takvog sredstva se smanjuje, a eksploatacija postaje nesigurna i neekonomična. Kod svih transportnih sredstava neispravnost u radu pojedinih dijelova, mehanizama i sklopova predstavlja stalnu potencijalnu opasnost koja može imati lakše ili teže posljedice ne samo za stroj, odnosno sredstvo već i za radnike koji ga opslužuju, pa se iz tih razloga neispravnosti bilo koje vrste moraju pravovremeno otkloniti. Sve ove neispravnosti predstavljaju prve znakove manjeg ili većeg oštećenja i ukazuju na mjesta nastanka, pa ih se ne smije olako shvatiti. Čimbenici koji utječu na trošenje su:

- konstrukcijsko-tehnološki čimbenici koji ovise o konstrukcijskim rješenjima pojedinih detalja, mehanizama ili agregata, dok tehnološki čimbenici ovise o kakvoći obrade radnih površina i vrste materijala (materijal kvalitetan, površina fino obrađena - dolazi do minimalnog trošenja elemenata).

- eksploatacijski čimbenici ovise između ostalog i o intenzitetu i karakteru upotrebe sredstva, kakvoći maziva, tehničkog održavanja itd.

Utjecaj uvjeta eksploatacije na tehničko stanje transportnih sredstava je jedan od čimbenika koji utječe na vijek trajanja i učestalost kvarova. Tako npr. često mijenjanje režima rada i opterećenja pogonskog mehanizma transportnog sredstva izaziva povećano trošenje dijelova i smanjuje njihov vijek trajanja. Također, povećanje temperature okolnog zraka vrlo često utječe na 
pregrijavanje motora, pa to uzrokuje smanjenje snage i brže trošenje dijelova. Na sličan način djeluju i niske temperature zraka okoline. U praksi se vrlo često događa da i najekonomičnija i vrlo kvalitetna transportna sredstva za vrlo kratko vrijeme zbog nebrige i slabog održavanja postanu neekonomična i nesigurna $u$ radu, smanjenog radnog učinka. Pravodobni i kvalitetni tehnički pregledi kao i otklanjanje uočenih kvarova vrlo često sprječavaju pojavu većih kvarova, a samim time je i sigurnost sredstva kao i upotrebno stanje povoljnije. Funkcija održavanja je pomoćna funkcija usmjerena većoj racionalizaciji poslovanja sa svrhom održanja tehničku sposobnosti strojeva i opreme u granicama tehnološke ispravnosti i točnosti. Pravilnim i redovnim provođenjem održavanja postiže se veća kakvoća proizvoda, stabilnija proizvodnja uz minimalne prekide, duži vijek trajanja opreme, sigurnost zaposlenih u radu, a sve to uz niže troškove poslovanja.

Strategije održavanja strojeva i opreme obuhvaćaju:

- Reaktivno održavanje - u slučaju kvara

- Preventivno ili redovito održavanje - na temelju proteklog vremena, radnih sati ili radnih ciklusa. To je održavanje koje se obavlja (pregledi, čišćenja, podmazivanja, zamjene ulja i rezervnih dijelova) prema unaprijed utvrđenim vremenskim ili radnim kriterijima, a s ciljem smanjenja mogućnosti kvara ili slabljenja svojstava nekog radnog dijela (stroja, uređaja, opreme).

- Prediktivno održavanje - prema mjerenim pokazateljima kakvoće rada stroja ili opreme. To je održavanje s predviđanjem mogućih grešaka na temelju mjerenih i analiziranih vrijednosti parametara koji su neposredni (direktni) ili posredni (indirektni) pokazatelji promjene stanja stroja ili opreme, a koji će utjecati na rad stroja ili opreme.

- Proaktivno pouzdano održavanje - praćenje procesnih veličina i pogonsko stanje strojeva (opreme)

Najveći problem za provedbu kvalitetnog održavanja jest to što postrojenje ne može proizvoditi za vrijeme održavanja (osim u slučaju manjeg zahvata, ali i tada je upitna mogućnost proizvodnje). Proizvodnja koja nema proizvod na izlazu iz procesa je gubitak, a samim time svako održavanje predstavlja gubitak. Temeljna filozofija je vrlo jednostavna: popraviti stroj prije no što se pokvari, te pratiti i analizirati neplanirane kvarove. Cilj je da se planiranjem unaprijed umanji učestalost, trajanje i cijena popravaka. Način kako smanjiti te gubitke 
S. Pliestić i sur.: Primjena infracrvene termografije u dijagnostici elektromotora na transporterima

može se riješiti jednostavnim sustavom praćenja i planiranja kojim se povećavaju čimbenici kontinuiranosti i neometanosti proizvodnih postupaka, što predstavlja značajan segment osiguranja kvalitetne i stabilne proizvodnje.

Primjena infracrvene (IC) termografije u dijagnostici

Do primjene IC termografije dnevni pregled transportera svodio se uglavnom na vizualni pregled pri pokretanju sredstva, primjerice elektromotora na transporteru. Otkriće infracrvenog (IC) zračenja vezano je uz W. Herschela koji je 1800. godine zapazio kako svjetlo koje prolazi kroz različito obojene filtre različito zagrijava stvari. Infracrveno (IC) zračenje dio je elektromagnetskog spektra i počinje ispod vidljivog dijela spektra na valnim duljinama $0.75 \mu \mathrm{m}$, a proteže se do preko $200 \mu \mathrm{m}$, kada IC zračenje prelazi u mikrovalno područje, što je gornji nivo radio valova. Za praktičnu primjenu u termografiji IC spektar je prihvatljiv u području $2 \mu \mathrm{m}$ do $13 \mu \mathrm{m}$. Kako IC zračenje nije vidljivo, za praktičnu primjenu mora se pretvoriti u neki drugi oblik energije: električnu, mehaničku ili kemijsku. Ta pretvorba odvija se u posebnim IC uređajima uz upotrebu detektora. Danas se proizvedeni uređaji za detekciju IC zračenja svrstavaju u dvije skupine: za mjerenje temperature (radiometrija) i za snimanje raspodjele temperature na površini objekata (termografija). Termografija je dakle, metoda bezkontaktnog mjerenja temperature površine objekta, snimanjem infracrvenog spektra zračenja površine. Svaki predmet sa svoje površine odaje toplinu infracrvenim zračenjem čija učestalost (frekvencija) ovisi o temperaturi objekta. Infracrvena kamera je uređaj koji omogućava snimanje zračenja sa površine nekog objekta i njegovo prikazivanje u vidljivom (optičkom) spektru. Termografijom se tijekom zadnjih godina bavi niz svjetskih i domaćih istraživača. Epperly i sur. (1997.) utvrđuju da IC termografija može pomoći da se proaktivno identificiraju kvarovi na opremi. Farsane i sur. (2000.) koriste IC termografiju u detekciji temperature stijenki elektromotora u cilju razvoja njegovog hlađenja. Balaras i Argiriou (2002.) istražuju uporabu infracrvene termografije u graditeljstvu, kao i primjenu IC termografije u području dijagnostike strojeva. Thomas (2004.) u ispitivanju elektromotora primjenjuje „on-line“ i „off-line“ sustave detekcije rada. Meola i Carlomagno (2004.) istražuju uporabu infracrvene termografije u područjima termodinamike fluida i kulturne baštine. Penrose (2005.) istražuje između ostalih i primjenu IC termografije u preventivnom održavanju elektromotora. Švaić i Boras (2006.) istražuju uporabu infracrvene termografije u području zaštite kulturne baštine. Zarreii i Bocarro (2008.) koriste 
S. Pliestić i sur.: Primjena infracrvene termografije u dijagnostici elektromotora na transporterima

sveobuhvatna dijagnostička testiranja crpki, pa primjenjuju i IC termografiju u ispitivanju. Krstulović - Opara i sur. (2010.) istražuju primjenu IC termografije $\mathrm{u}$ analizi i raspodjeli naprezanja u zavarenim spojevima aluminijskih ploča. Mikulić i sur. (2010.) istražuju mogućnost uporabe infracrvene termografije u provođenju energetskog certificiranja zgrada.

\section{METODE}

Istraživanja su provedena na elektromotorno pogonjenom pužnom dodavaču (dozatoru). Broj okreta elektromotora reduciran je na $300 \mathrm{~min}^{-1}$ primjenom reduktora prijenosnog odnosa 5.26/1. Pužni dodavač je dužine $l=230 \mathrm{~mm}$, promjera pužnice $\varnothing=35 \mathrm{~mm}$, promjera osovine $\varnothing=8.5 \mathrm{~mm}$, koraka pužnice $s$ $=25 \mathrm{~mm}$. Promjer kućišta (cijevi) pužnog dodavača $\varnothing=37.5 \mathrm{~mm}$.

\section{Mjerna oprema}

Rad elektromotora pužnog dodavača analiziran je primjenom infracrvene kamere Horiba II-1064A. IC kamera opremljena je detektorom sa senzorom od $64(8 * 8)$ elementa (polja). Mjerno temperaturno područje IC kamere je od -50 do $1000^{\circ} \mathrm{C}$, uz točnost $\pm 2{ }^{\circ} \mathrm{C}$. Spektralni raspon kamere je od 8 do $16 \mu \mathrm{m}$.

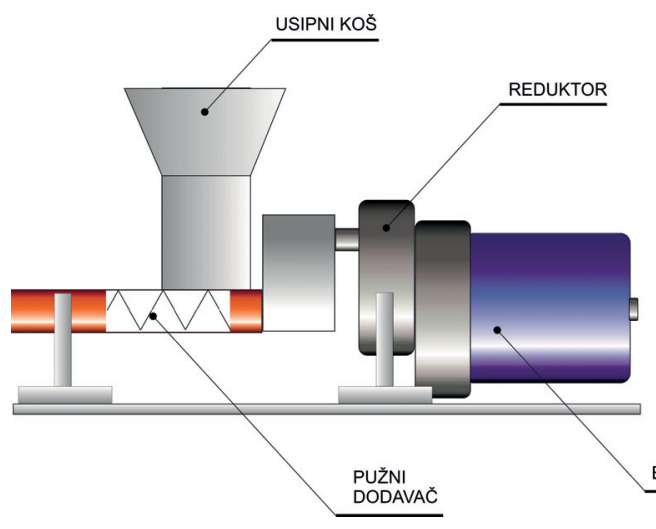

Elektromotorno pogonjeni pužni dodavač Screw conveyor with electric motor drive

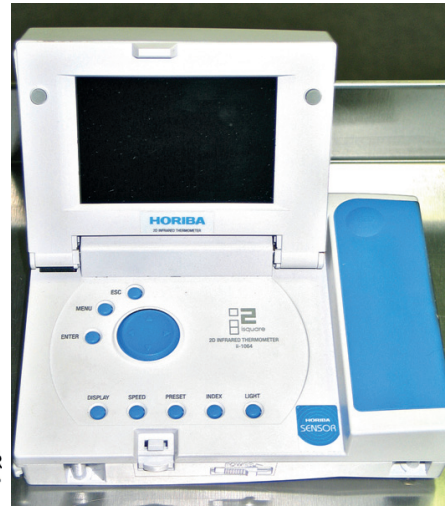

Infracrvena kamera Horiba II-1064A Infrared camera Horiba II-1064A

Slika 1. Oprema i mjerni uređaj

Figure 1 Equipment and measuring device 
S. Pliestić i sur.: Primjena infracrvene termografije u dijagnostici elektromotora na transporterima

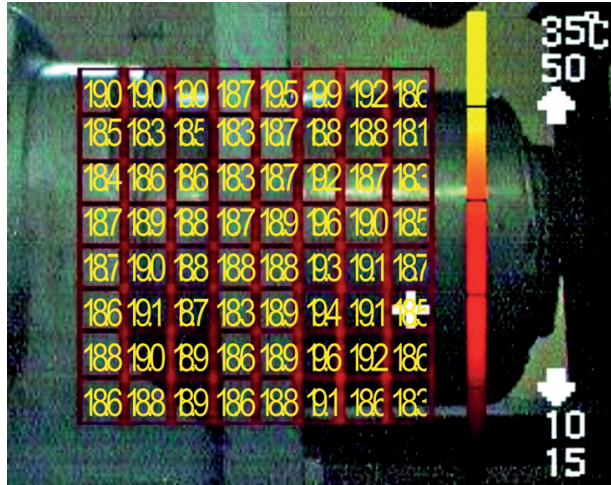

Temperatura elektromotora na početku rada (0 min.) -

The temperature of the electric motor at start-up (0 min.)

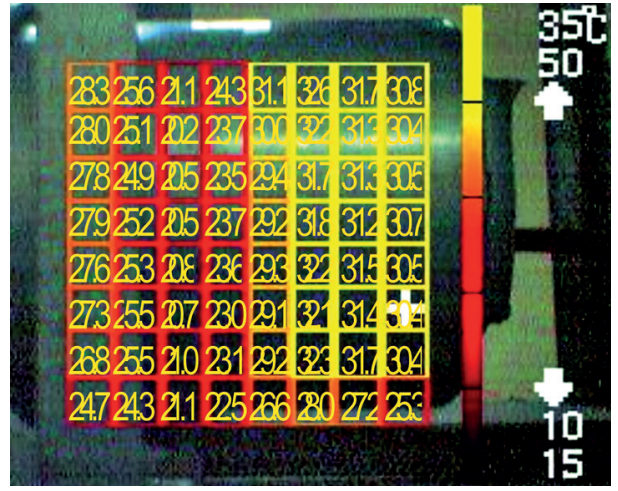

Temperatura elektromotora nakon 40 minuta rada -

The temperature of the electric motor after 40 minutes of work

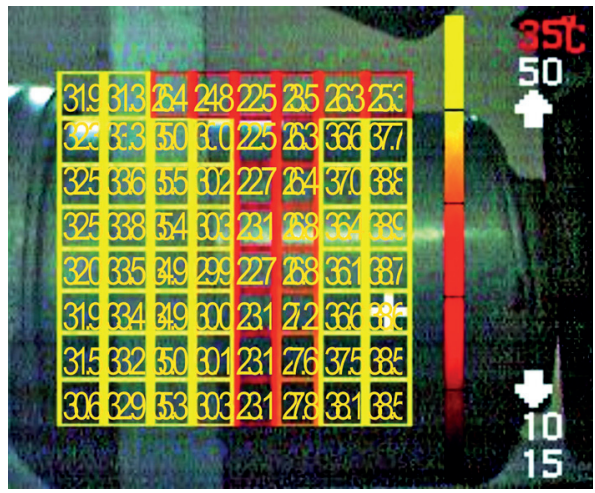

Temperatura elektromotora nakon 1 sat i 40 minuta rada -

The temperature of the electric motor after 1 hour and 40 minutes of work

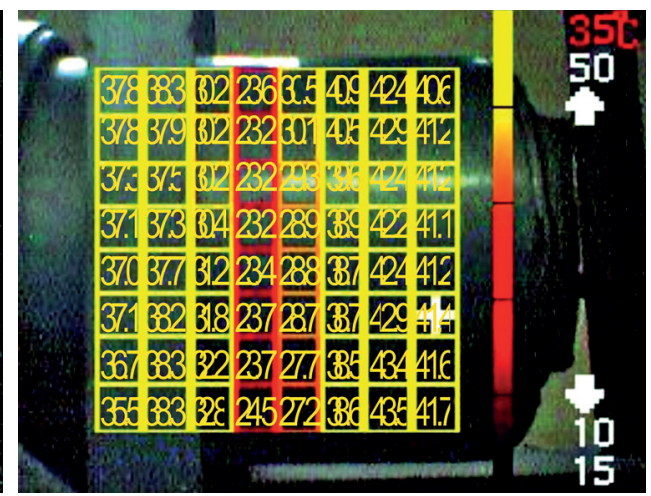

Temperatura elektromotora nakon 2 sata i 40 minuta rada The temperature of the electric motor after 2 hours and 40 minutes of work

Slika 2. Rezultati mjerenja

Figure 2 Results of measurements 
S. Pliestić i sur.: Primjena infracrvene termografije u dijagnostici elektromotora na transporterima

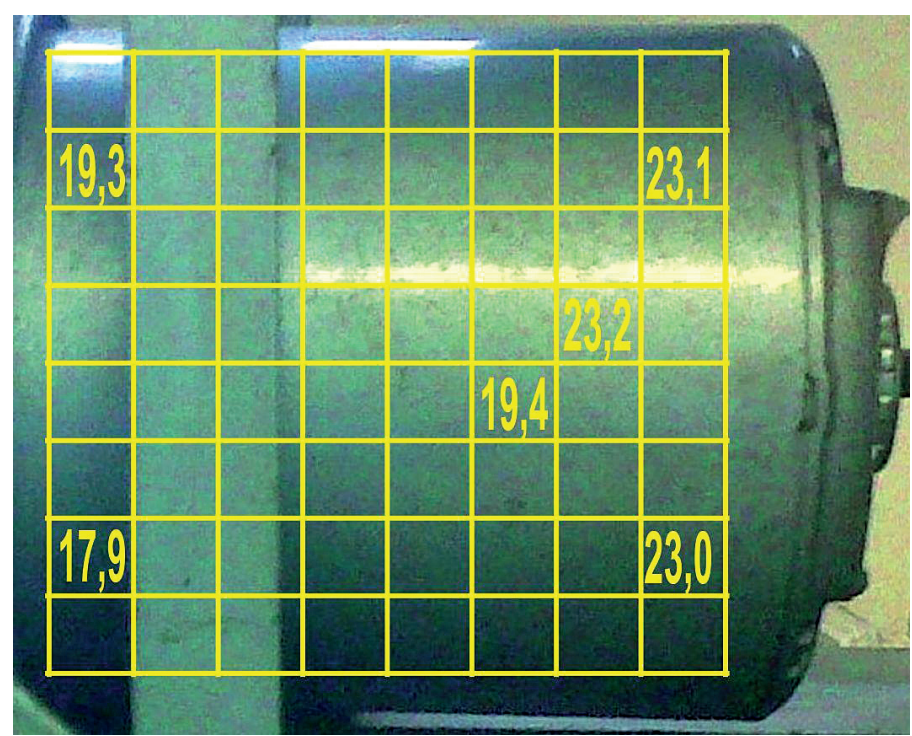

Slika 3. Temperatura razlika elektromotora u odnosu na početak rada i nakon 2 sata i 40 minuta rada na ključnim mjestima

Figure 3 The temperature difference at key locations of electric motor between start of work and after 2 hours and 40 minutes of work

Porast temperatura ostvaren je u rasponu od 1.95 do 2.27 puta u odnosu na početne temperature elektromotora.

\section{RASPRAVA}

Porast temperature elektromotora na pužnom dodavaču (transporteru) može imati niz implikacija. Električni motori ovise o pravilnoj usklađenosti između osovina za dugoročan i efikasan rad. Pomak uzrokuje opterećenje na stražnjem ležaju motora koje može dovesti do prijevremenog oštećenja ležaja i povećanja troškova rada. Osim toga, problemi kao što su pogrešni ležajevi, nepravilno podmazivanje, nepravilna uporaba ili normalno trošenje (habanje), dovest će do trenja koje uzrokuje prekomjernu toplinu i temperaturne razlike. Loše podmazivanje generira toplinu koja uništava preostalo mazivo, dakle dolazi do povećanja trenja i temperature površina koje dolaze u dodir.

Motori se odabiru između ostalog i prema njihovoj najvećoj dopuštenoj radnoj temperaturi, koja se pak određuje prema vrsti električnih izolacijskih 
S. Pliestić i sur.: Primjena infracrvene termografije u dijagnostici elektromotora na transporterima

materijala u motoru. Sama izolacijska svojstva rapidno se smanjuju kada se prijeđe granična vrijednost radne temperature. Za svakih $10{ }^{\circ} \mathrm{C}$ porasta radne temperature smanjuje se predviđeni radni vijek motora za 50\% (Snell, 1997). Ocjena motora određuje se na najtoplijem mjestu izolacijskog sustava u motoru, u radu na temperaturi okoline od $40{ }^{\circ} \mathrm{C}$. Temperatura na vanjskoj oplati motora je približno $20{ }^{\circ} \mathrm{C}$ niža od temperature unutar motora. Prekomjerno povećanje temperature ili neujednačeno zagrijavanje može biti rezultat induktivne neravnoteže u statoru poradi kratko spojene zavojnice. Kratko spojene zavojnice u sinkronom motoru imat će hladne polove na rotoru, dok su topliji polovi povezani s oštećenim lamelama polova. Neujednačeno zagrijavanje između brzine vrtnje i kliznih prstenova na motoru izmjenične struje može biti uzrokovano kratkim spojem u kolutu rotora. Zagrijavanje istosmjernog motora može ukazati na povećani otpor, što može uzrokovati probleme sa zakretnim momentom i brzinom. Vrući vodiči motora mogu biti rezultat kratkog spoja u namotima statora ili gubitka induktiviteta $\mathrm{u}$ istosmjernom polju. Prekomjerni porast temperature poveznih električnih vodiča u kaveznom induktivnom motoru može biti uzrokovan polomljenim ili oštećenim dijelovima rotora (lamela). Povećanje količine prašine unutar motora također može uzrokovati prekomjerni porast temperature. Osim toga za točniju dijagnostiku preporuča se koristiti i druge tehnologije, posebice trenutnu analizu motora i analizu vibracija. Dobiveni rezultati istraživanja su u skladu s rezultatima istraživanja Epperly, Heberlein i Eads (1997.), Farsane i sur. (2000.), Balaras i Argiriou (2002.), Penrose (2005.), Zarreii i Bocarro (2008.) koji utvrđuju da IC termografija može pomoći da se proaktivno identificiraju kvarovi na opremi, odnosno da IC termografija ima primjenu u području dijagnostike strojeva.

Primjena IC termografije u proizvodnji krmnih smjesa

Otkrivanje tehničkih grešaka, kvarova i propusta u linijama za proizvodnju i transport krmnih smjesa, kao i stanje u nastambama za životinje mogućnosti su primjene IC termografije. Ispitivanjem toplinskih promjena u materijalima lako se utvrđuje toplinski tok, upijanje topline ili temperatura strojeva, uređaja i opreme u linijama za proizvodnju krmnih smjesa. Mjerljivost temperaturnih anomalija omogućuje nadzor punih skladišta, silosa, prati tok materijala i njegovo toplinsko stanje kroz transportere, locira zastoje materijala, kritična mjesta. Snimanjem nevidljivog toplinskog zračenja odmah se uočava preopterećenje strujnih vodova, pregrijavanje elektromotora i generatora, istrošenost ležajeva ili pojačano trenje na pokretnim dijelovima strojeva. 
S. Pliestić i sur.: Primjena infracrvene termografije u dijagnostici elektromotora na transporterima

\section{ZAKLJUCAK}

1. Infracrvena (IC) termografija može biti kvalitetan alat za brzu i točnu dijagnostiku stanja elektromotora, a mjesto kvara može se odrediti u značajno kraćem vremenu od dosadašnjeg.

2. Analiza IC termografijom obavlja se u realnom vremenu, beskontaktna je i ne remeti se toplinska ravnoteža.

3. Nadzor odnosno inspekciju strojeva, uređaja i opreme IC termografijom moguće je izvesti u radu strojeva, uređaja i opreme.

4. IC termografijom moguće je identificirati promjene koje su inače nevidljive.

5. Primjenom IC termografije održavanje strojeva, uređaja i opreme postaje prediktivno. Kritična mjesta ili neispravni strojevi ili oprema pravovremeno su uočeni pa ih je moguće pravovremeno popraviti prije no što prouzroče ozbiljnu štetu.

6. Za razliku od interventnog održavanja (zamjena dijelova kada se kvar dogodi), kod prediktivnog održavanja vrijeme za popravak i troškovi popravka su značajno manji.

7. Ponekad nedostatak IC termografije može biti to što se mjerenje temperature odvija na površini objekta.

8. Također, rezultati IC termografije ovise o svojstvu: objekta (emisija, refleksija i propusnost promatrane površine), potom mediju između objekta i kamere, udaljenosti objekta, kamere (osjetljivost, točnost)

\section{LITERATURA:}

1. Balaras, C. A., Argiriou, A. A. (2002.): Infrared thermography for building diagnostics Energy \& Buildings, Vol. 34, p. 171-184,. Elsevier, Netherlands

2. Epperly, R. A. Heberlein, G. E. ; Eads, L. G. (1997.): A tool for reliability and safety: predict and prevent equipment failures with thermography; Petroleum and Chemical Industry Conference, Conference Papers, p. 59 - 68. The Institute of Electrical and Electronics Engineers Incorporated Industry Applications Society $44^{\text {th }}$ Annual; 15 - 17. IX. 1997. Banff, Alta.

3. Farsane, K., Desevaux, P., Panday, P. K. (2000.): Experimental study of the cooling of a closed type electric motor; Aplied Thermal Engineering, Vol. 20, No. 14, p. 1321-1334, Elsevier, Netherlands 
S. Pliestić i sur.: Primjena infracrvene termografije u dijagnostici elektromotora na transporterima

4. Krstulovic-Opara, L., Klarin, B., Neves, P., Domazet, Z. (2010.): Thermal imaging and thermal stress analysis of the impact damage of composite materials; Proceedings of Fourth International Conference on Engineering Failure Analysis, ICEFA IV, 4. - 7. July, Cambridge, United Kingdom

5. Meola, C., Carlomagno, G. M. (2004.): Recent advances in the use of infrared thermography, Measurement Science and Technology, Vol. 15., No 9., United Kingdom

6. Mikulić, D., Milovanović, B., Šimetin, V., Marđetko Škoro, N. (2010.): Proces energetske certifikacije zgrada u hrvatskoj - primjena infracrvene termografije; Proceedings of Fourth International Conference on Engineering Failure Analysis, ICEFA IV, 4. - 7. July, Cambridge, United Kingdom

7. Penrose, H. W. (2005.): AC Motor Testing and Predictive Maintenance, The Institute of Electrical Motor Diagnostics Inc., USA

8. Snell, J. R. (1997.): Infrared inspection of motors; Think Thermally, Snell Infrared's Newsletter, December 1997., Vermont, USA

9. Švaić, S., Boras, I. (2006.): IC termografija-primjena kod očuvanja kulturne baštine. Fakultet strojarstva i brodogradnje, Zagreb

10. Thomas, T. M. (2004.): On-Line and Off-Line Testing of Electric Motors; Baker Instrument Company, Fort Collins, Colorado.

11. Zarreii, M., Bocarro, R. (2008.): From Pump Drawdown Testing to Comprehensive Diagnostic Testing; Proceedings of the Water Environment Federation, WEFTEC 2008: Session 101 through Session 115, pp. 7902-7918 (17); Izdavač/Publisher Water Environment Federation.

\section{Adrese autora - Authors' addresses:}

Prof. dr. sc. Stjepan Pliestić, e-mail: spliestic@agr.hr
Primljeno - Received:

25.05.2017.

Doc. dr. sc. Ante Galić, e-mail: agalic@agr.hr

Prof. dr. sc. Nadica Dobričević, e-mail: ndobricevic@agr.hr

Izv. prof. dr. sc. Sandra Voća, e-mail: svoca@agr.hr

Doc. dr. sc. Jana Šic Žlabur, e-mail: jszlabur@agr.hr

Sveučilište u Zagrebu, Agronomski fakultet

Svetošimunska cesta 25, 10000 Zagreb

Prof. dr. sc. Franjo Jović, e-mail: fjovic@inet.hr

Sveučilište J. J. Strossmayera u Osijeku, Elektrotehnički fakultet

Kneza Trpimira 2B, 31000 Osijek 